\title{
Um estudo sobre as relações entre atitudes, gênero, série e desempenho em exercícios e problemas envolvendo frações
}

\author{
A study on the relationship between attitudes, gender and performance in exercises and \\ problems involving fractions
}

\author{
Andresa Maria Justulin \\ andresa_justulin@yahoo.com.br
}

\begin{abstract}
Resumo
O presente trabalho investigou relações entre o desempenho na solução de problemas e exercícios sobre frações e variáveis como: as atitudes em relação à Matemática, as atitudes em relação a frações, o gênero e a série. Participaram da pesquisa 95 estudantes do Ensino Médio. Os instrumentos utilizados foram: escalas de atitudes em relação à Matemática e em relação a Frações e três provas de Matemática: de algoritmo, conceitual e envolvendo problemas. Os resultados indicaram que as correlações mais fortes foram entre as notas na prova de algoritmo e dos problemas, escalas de atitudes em relação à Matemática e em relação a frações e, em menor grau, entre a nota dos problemas e a escala de frações. Com relação ao gênero, não foram encontradas diferenças significativas. Observou-se também que o desempenho geral tende a melhorar conforme a série, ao contrário do que acontece com as atitudes em relação à matemática.
\end{abstract}

Palavras-Chave: Educação matemática; Desempenho; Atitudes; Frações; Solução de problemas.

\begin{abstract}
The present study research investigated relations between the performance in the solution of problems and exercises about fractions and variables such as: the attitudes in relation to mathematics, the attitudes in relation to fractions, the genre and the grade. 95 students of High School from a public school participated in the research. The instruments used were: scale of attitudes in relation to mathematics and in relation to fractions and three mathematical test: of algorithm, of conceptual and involving problems. The results indicated that the strongest correlations were between the marks in the test of algorithm and of the, between the scales of attitudes in relation to mathematics and in relation to fraction and in smaller degree, between the mark of the problems and the scale of fractions. In relation to the genre, no significant differences were found. Also, it was observed that the general performance tends to increase according to the grade, in contrast of what happens to the attitudes in relation to mathematics.
\end{abstract}

Keywords: Mathematic education; Performance; Attitudes; Fraction; Solution of problems.

\section{Introdução}

Os Parâmetros Curriculares Nacionais/ Temas Transversais (BRASIL, 1998, p. 187) recomendam que “(...) mais do que informações e conceitos, a escola se proponha a trabalhar com atitudes, com formação de valores, com o ensino e aprendizagem de procedimentos". Dessa forma, as diversas disciplinas devem dar atenção não apenas aos conteúdos, mas, inclusive, aos fatores afetivos que podem contribuir com o desempenho do aluno e, por isso, devem ser considerados e desenvolvidos em sala de aula.

Quanto ao desempenho dos estudantes, existe uma crença, de acordo com Brito (1996), de que os indivíduos do gênero masculino saem-se melhor em Matemática do que o 
gênero feminino. Assim, os meninos solucionariam problemas e exercícios com mais facilidade que as meninas.

Considerando-se que a solução de problemas pode contribuir para a formação do estudante, através da motivação e mobilização de conceitos aprendidos e conhecimentos prévios, esse estudo investigou as relações entre gênero, a série e o desempenho na solução de problemas e em exercícios envolvendo frações.

Quanto à escolha dos Números Racionais, esta se deu por ser um conteúdo que parece provocar aversão e dificuldade nos estudantes do Ensino Médio. Oliveira (1996), Prado (2000) e Catalani (2002) apontaram que alunos e professores têm encontrado dificuldade em relação ao ensino de frações. Embora os números fracionários estejam presentes no cotidiano, parece que os estudantes não gostam ou não se sentem familiarizados ao trabalhar com eles.

\section{Fundamentação teórica}

\section{Atitudes em relação à Matemática}

Brito (1996), em sua tese de livre docência, realizou um amplo estudo sobre as atitudes em relação à Matemática e mostrou que a literatura especializada envolvendo este tema traz várias definições diferentes para o conceito de atitudes, variando de acordo com o autor e a época.

A formação de atitudes positivas em qualquer disciplina parece motivar o estudante, fazendo com que o mesmo se interesse pelos conteúdos tratados. Para Coll (1998), “as atitudes guiam os processos perceptivos e cognitivos que conduzem à aprendizagem de qualquer tipo de conteúdo educacional seja conceitual, procedimental ou atitudinal" (p.136).

Krutetskii (1976) e Klausmeier (1977) reafirmam que as atitudes são uma espécie de "condição necessária" para que o indivíduo tenha um bom aproveitamento na realização de uma tarefa. O último autor aponta que, se um indivíduo possui uma atitude favorável em relação a alguma coisa, procurará se aproximar dela e irá defendê-la, enquanto aquele que tem uma atitude desfavorável irá evitá-la (p.417).

Neste trabalho, considerou-se que:

Atitude é uma disposição pessoal, idiossincrática, presente em todos os indivíduos, dirigida a objetos, eventos ou pessoas, que assume diferente direção e intensidade de acordo com as experiências do indivíduo. Além disso, apresenta componentes de domínio afetivo, cognitivo e motor (BRITO, 1996, p.11). 
As atitudes não são gerais e possuem sempre um referente, ou seja, é sempre "atitude em relação a" e, sendo um evento interno, aprendido, com componentes cognitivos e afetivos que variam em intensidade, é dirigida a um objeto específico.

O desempenho dos alunos está diretamente relacionado ao "gostar" da disciplina; assim, é provável que os alunos que apresentam atitudes positivas em relação à Matemática consigam um desempenho melhor do que aqueles que nutrem um sentimento de aversão à Matemática.

Gonçalez (2000), Jesus (2005) e Vianna (2005) identificaram em seus trabalhos que alunos com atitudes mais positivas tendem a ter melhor desempenho que os alunos com atitudes mais negativas.

A influência dos pais e amigos e as interferências mútuas entre as atitudes dos professores e dos alunos são de igual relevância no surgimento das atitudes em relação à Matemática. Dienes (1970 apud ARDILES, 2007, p.10), destacou que a maneira como os professores ministram suas aulas pode ser um dos motivos para que muitas pessoas não gostem de Matemática.

As atitudes dos professores também têm grande influência nas atitudes de seus alunos e em seu desempenho, de acordo com Aiken e Dreger (1961 apud BRITO, 1996); professores impacientes, hostis e que não dominam o conteúdo podem influir no surgimento de atitudes negativas no educando.

Os pais podem afetar as atitudes de seus filhos através de suas próprias atitudes em relação à Matemática, além de que o excesso de expectativa pode levar os estudantes a desenvolver um alto grau de ansiedade. Macedo (1994) apontou que, para a psicologia social, a família é revestida de importância, dado que é o primeiro ambiente com que a criança tem contato e onde se dá a sua socialização primária. Os primeiros contatos com elementos matemáticos ocorrem no ambiente familiar e as primeiras impressões provavelmente irão interferir na formação de atitudes e seus componentes afetivos, cognitivos e sociais.

Alguns trabalhos encontrados na literatura educacional a respeito das diferenças entre os gêneros com relação às atitudes e habilidades matemáticas, como os de Araújo (1999), Postigo, Pérez Echeverría e Sanz (1999), afirmam a existência de diferenças, mas estas têm pouca importância ao longo da vida dos estudantes, ressaltando ser este mais um problema cultural. Para Brito (1996),

Culturalmente, são atribuídos "rótulos" aos indivíduos e afirmações que não são confirmadas através de pesquisas passam a ser consideradas como verdadeiras. 
Assim, cristalizou-se a idéia de que a habilidade verbal é uma característica feminina e a habilidade matemática é uma característica masculina. Dentro desta concepção, os homens deveriam apresentar alta habilidade matemática e baixa habilidade verbal enquanto as mulheres apresentariam alta habilidade verbal e baixa habilidade matemática (p.75).

Os contextos familiares caracterizam-se por diferentes processos e implicações para os meninos e meninas. As implicações das diferenças de gêneros e interesses, aspirações de carreira e desempenho têm merecido várias pesquisas que relatam que os sujeitos do sexo feminino são menos confiantes em suas habilidades matemáticas e procuram menos as carreiras relacionadas com a área de exatas, conforme Araújo (1999).

Embora a maioria dos trabalhos encontre pouca relação entre gênero e desempenho, aponta-se que algumas diferenças entre os gêneros se acentuam em determinadas tarefas ou habilidades como nos cálculos e na solução de problemas.

\section{A solução de problemas X Exercícios}

De acordo com Brito (2006), o ponto de partida para se solucionar um determinado problema é sempre uma situação desconhecida que faz com que o indivíduo mobilize sua estrutura cognitiva, buscando os elementos necessários para chegar à solução.

Muitas confusões e divergências ocorrem para definir a solução de problemas e as etapas que envolvem a mesma. Uma situação-problema só se configura como um problema quando o estudante é motivado a encontrar o estado final.

Para resolver exercícios, geralmente contamos com a ajuda de algoritmos ou técnicas que acabam sendo repetidas pelos alunos inúmeras vezes e apresentam sempre um método óbvio de solução. Essa seria a característica fundamental para a diferenciação entre problemas e exercícios. Echeverría (1998, p. 49) afirma que "os exercícios servem para consolidar e automatizar certas técnicas, habilidades e procedimentos para a posterior solução de problemas (...) dificilmente podem servir para a aprendizagem e compreensão de conceitos". De acordo com Lima (2001), um problema pode nunca ser adequado a todos os alunos de uma classe, pois os estudantes sempre apresentarão conhecimentos diversos sobre um mesmo assunto e estágios de desenvolvimento intelectual diferenciados. Portanto, o professor deve estar atento na escolha de problemas adequados e procurar motivar os educandos.

Polya (1986) estabelece que o processo da solução de um problema envolve quatro passos necessários. Primeiramente, deve ocorrer a compreensão do problema, o entendimento das palavras, da linguagem e da situação para que ocorra a concepção de um plano. Em seguida, o indivíduo executa o plano, ou seja, verifica se aquilo que pretendia resolve o 
problema ou não. O último passo constitui-se de uma visão retrospectiva do problema, em que se verifica o resultado obtido e sua compatibilidade com o enunciado e seus elementos.

Sternberg (2000) destaca que as pessoas só se interessam em resolver problemas quando é preciso superar obstáculos para se atingir um determinado objetivo. Além disso, descreve um ciclo de resolução de problemas, ou seja, esquematiza alguns recursos utilizados para solucionar um problema. São eles: (1) Identificação do problema; (2) Definição e representação do problema; (3) Formulação da estratégia; (4) Organização da informação; (5) Alocação de recursos; (6) Monitorização e (7) Avaliação.

Se o aluno não passar por essas etapas durante a solução de um problema, certamente encontrará algumas dificuldades para obter resultados satisfatórios. As etapas apresentadas para solucionar um problema parecem ser fundamentais para se obter êxito. Dessa forma, ensinar o aluno a planejar as etapas de solução de um problema influenciará não apenas em seu desempenho, como também em suas atitudes.

\section{O Ensino de Frações}

Os trabalhos de Oliveira (1996), Lima (1996), Prado (2000), Catalani (2002), Merlini (2005), apontam dificuldades dos estudantes com o conceito de fração. Algumas das falhas no entendimento dos alunos sobre esse conceito devem-se à complexidade e à forma de abordagem, que, muitas vezes, enfatiza a operacionalidade técnica. Com isso, o estudante pode desenvolver aversão a esse conceito e à Matemática, o que frequentemente o impede de compreender, desenvolver raciocínios e solucionar um determinado problema proposto.

A partir dessas pesquisas, alguns autores dão indícios de que o conhecimento do professor a respeito de frações e a forma de ensiná-lo podem levar a uma aprendizagem de conceitos fragmentados ou pautados em aspectos mecânicos.

O ensino das frações, de acordo com Prado (2000), deve ser centrado "na (re)criação dos conceitos matemáticos, destacando como elemento importante para esta o caminho do movimento da história do conceito" (p. 56). Seria ideal que as crianças passassem pela mesma lógica do desenvolvimento do conceito de fração. Dessa forma, e por meio da experiência com situações envolvendo frações ao longo da escolaridade, o aluno vai compreendendo a linguagem, os símbolos e torna esses elementos significativos.

Os livros didáticos, em sua maioria, trazem ainda um grande formalismo e apresentam uma Matemática mecanicista. A história dos Números Racionais é pouco tratada ou utilizada apenas como ilustração e não como (re)construção, conforme Prado (2000). 
Lima (1996) aponta que o domínio dos conceitos por parte do professor pode ajudar na aprendizagem do aluno. A autora, no entanto, afirma que "a ideia de parte de alguma coisa deve ser a chave para o ensino de frações" (p. 24).

Oliveira (1996), Nacarato et al (2004), Santos (2005), Maciel e Câmara (2007) citam os trabalhos de Kieren (1976, 1981, 1993). Para este autor e outros como Behr et al. (1983) e Nunes e Bryant (1996), a ideia de fração como parte de alguma coisa é apenas uma das várias interpretações para esse conceito.

Os Parâmetros Curriculares Nacionais, assim como os diferentes pesquisadores, de acordo com Nacarato et al (2004), apontam quatro significados centrais ao estudo das frações: quociente, razão, parte-todo e operador. A maioria dos trabalhos utiliza como referencial teórico os trabalhos de Kieren.

Nunes et al. (2003) identificam, como significados centrais e que devem ser levados em consideração no ensino e aprendizagem de frações: medidas, parte-todo, quociente, número e operador multiplicativo.

\section{Sujeitos, métodos, material e procedimento}

O estudo aqui apresentado foi desenvolvido tendo como sujeitos 95 alunos do Ensino Médio. Foram utilizados como instrumentos: a) escala de atitudes em relação à Matemática; b) escala de atitudes em relação a Frações; c) questionário informativo; d) prova matemática (para aplicação direta do algoritmo); e) prova conceitual (para abordar alguns conceitos e procedimentos, sem o uso do Mínimo Múltiplo Comum (m.m.c.); f) prova matemática (de solução de problemas); g) o "pensar em voz alta".

A primeira etapa da pesquisa foi realizada em três sessões. Inicialmente, os alunos deveriam responder o questionário pessoal, a escala de atitudes em relação à Matemática elaborada por Aiken (1961) e revista por Aiken e Dreger em 1961, traduzida, testada e adaptada por Brito (1996) e realizar a prova de Matemática através do recurso do m.m.c.

$\mathrm{Na}$ segunda sessão, os estudantes realizaram a prova de Matemática, na qual era solicitado que não resolvessem através do m.m.c. e, em seguida, solucionaram os problemas.

Na última sessão, os estudantes responderam a escala de atitudes em relação a Frações. Essa escala foi adaptada e validada com o objetivo de avaliar as atitudes em relação à Fração com ênfase na solução de problemas. A aplicação dessas duas escalas possibilitou o estudo de possíveis correlações e análise das atitudes em relação à Matemática e a Frações. 
$\mathrm{Na}$ segunda etapa da pesquisa, após a correção das provas, foram selecionados alguns alunos para participar do "pensar em voz alta", de acordo com o desempenho obtido (média entre a prova Matemática de algoritmo e a prova de problemas): 2 (dois) participantes com nota inferior à média geral, 2 (dois) participantes com nota superior à média geral e 1 (um) participante com nota aproximadamente entre a média dos 4 (quatro) sujeitos selecionados.

Os participantes selecionados para o "pensar em voz alta", foram orientados a resolver a prova Matemática (algoritmo), a prova de Matemática (Conceitual e procedimentos diversos) e a Prova de Matemática de problemas novamente. Para isso, uma prova em branco foi fornecida e solicitou-se que o aluno explicasse o que fazia como se estivesse "pensando em voz alta", podendo ser interrogado para obter, de forma mais precisa, o seu raciocínio e procedimento realizado.

O "pensar em voz alta" é um método pelo qual o sujeito é solicitado a verbalizar, enquanto soluciona um problema, e essa solicitação é repetida, se necessário, durante todo o processo de solução do problema, como uma maneira de encorajar o sujeito a relatar, de maneira precisa, os procedimentos que está executando. $\mathrm{O}$ pesquisador pode formular questões para o sujeito de forma a esclarecer os procedimentos que estão sendo utilizados e as relações entre eles.

O método consiste em solicitar aos sujeitos que pensem em voz alta enquanto estão solucionando um problema e, posteriormente analisar os protocolos verbais resultantes (BRITO, 2001 apud LIMA, 2001, p.54).

O "pensar em voz alta", sugerido por Krutestskii (1976), foi utilizado em várias pesquisas, como as de Araújo (1999), Utsumi (2000), Lima (2001) e Dobarro (2007). O objetivo da utilização desse método é buscar uma melhor compreensão do pensamento do aluno quando o mesmo está diante de uma tarefa de solução de problemas.

\section{Alguns Resultados}

Para a análise estatística dos dados foi utilizado software SPSS - Statistical Package for Social Science (NORUSIS, 1993).

A análise dos dados obtidos mostrou que a pontuação na escala de atitudes variou de 22 a 78 pontos, com uma média de 49,51 e desvio padrão de 14,48 pontos, numa escala de 20 a 80 pontos. Já na escala de atitudes em relação a Frações, a pontuação média foi de 44,6, com desvio padrão de 10,5 pontos. Tomando como referência o ponto médio de 50 , verificase que esse grupo mostra atitudes mais negativas do que positivas. 
Os resultados do teste $t$-student ${ }^{1}$ indicam não haver diferença significativa entre os gêneros na pontuação média na escala de atitudes em relação à Matemática $(t(93)=-0,321 ; p$ $=0,749)$, nem na pontuação média da escala de frações $(t(92)=0,514 ; p=0,514)$, como mostra a Tabela 1.

Tabela 1: Estatísticas da pontuação nas escalas de atitudes, por gênero

\begin{tabular}{lllll}
\hline Escala & Gênero & $\mathrm{N}$ & Média & Desvio padrão \\
\hline Escala Matemática & Feminino & 45 & 49,00 & 14,84 \\
& Masculino & 50 & 49,96 & 14,28 \\
Escala Frações & Feminino & 44 & 44,57 & 8,48 \\
& Masculino & 50 & 45,86 & 10,40 \\
\hline
\end{tabular}

As análises da pontuação na escala de atitudes e na prova de Matemática, de forma separada, deram indícios de que há uma relação dessas variáveis por série e, mais tenuemente, com gênero. A correlação geral entre essas variáveis foi muito baixa, embora significativa ( $\mathrm{r}$ $=0,305 ; p=0,003)$, como mostra a Figura 1 .

Figura 1: Relação entre as atitudes e desempenho na prova

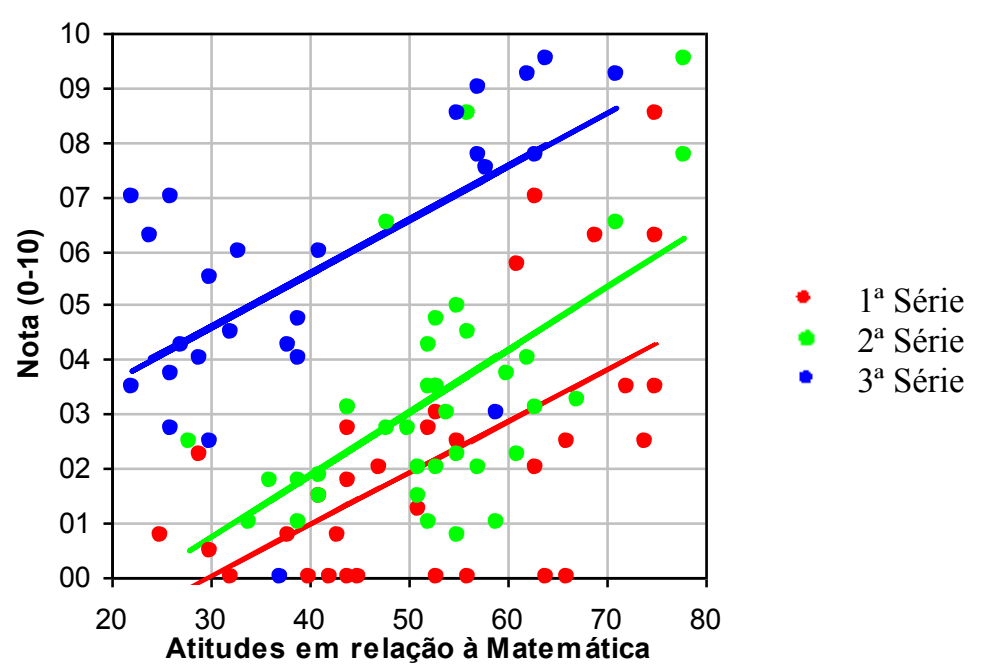

Fonte: Dados da pesquisa.

Analisando o desempenho nas duas provas, conforme mostra a Tabela 2, observa-se que os alunos apresentaram melhor desempenho na prova de algoritmo (Figura 2) do que na prova contendo os problemas (Figura 3), na qual a maioria dos alunos obteve notas abaixo de cinco.

${ }^{1} \mathrm{O}$ teste t-student verifica se uma determinada diferença identificada entre medidas de dois grupos é estatisticamente significante. 
Figura 2: Nota no desempenho na prova de algoritmo

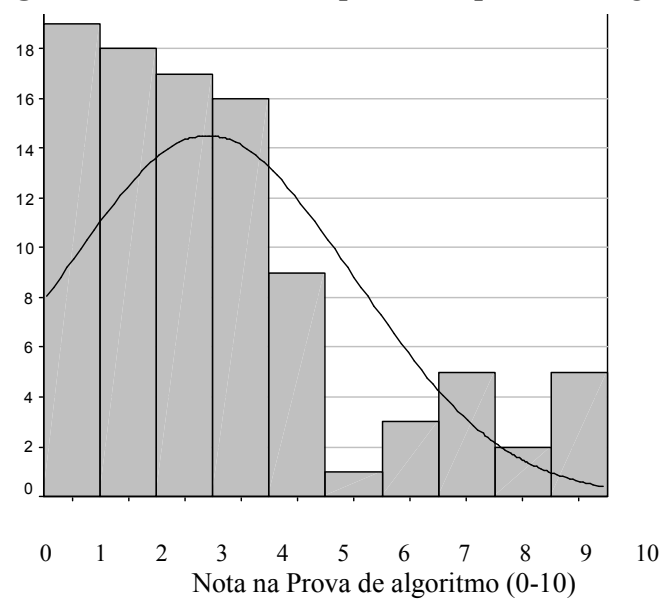

Figura 3: Nota no desempenho na prova de problemas

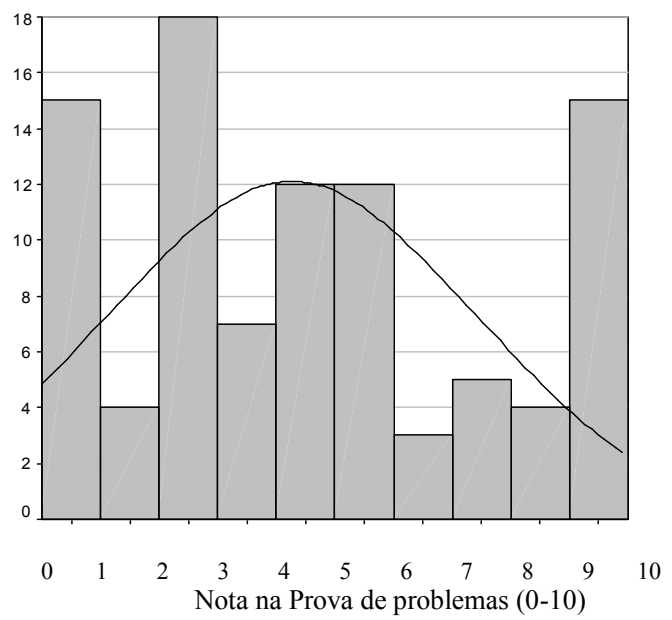

Fonte: Dados da pesquisa.

Tabela 2: Estatísticas da nota na prova de Matemática

\begin{tabular}{llllll}
\hline Prova & N & Mínimo & Máximo & Média & Desvio padrão \\
\hline Algoritmo & 95 & 0 & 10 & 4,2632 & 3,1249 \\
Problemas & 95 & 0 & 10 & 2,9053 & 2,6060 \\
\hline
\end{tabular}

Fonte: Dados da pesquisa.

A análise do desempenho na prova de algoritmo mostra que as diferenças por série $(\mathrm{F}(2,89)=27,043 ; p=0,000)$ foram significativas, mas não foram encontradas diferenças por gênero $(F(1,89)=0,754 ; p=0,388)$, nem interação série e gênero $(F(2,89)=1,816 ; p=$ $0,169)$, de acordo com a figura 4.

O desempenho na prova de problemas, além da diferença entre as séries $(\mathrm{F}(2,89)=$ $4,428 ; p=0,015)$, foi encontrada diferença por gênero $(\mathrm{F}(1,89)=7,449 ; p=0,008)$, mas não foi encontrada interação série e gênero $(\mathrm{F}(2,89)=1,456 ; p=0,239)$, conforme figura 5 . 
Figura 4: Nota média na prova com questões de algoritmo, por série e gênero.

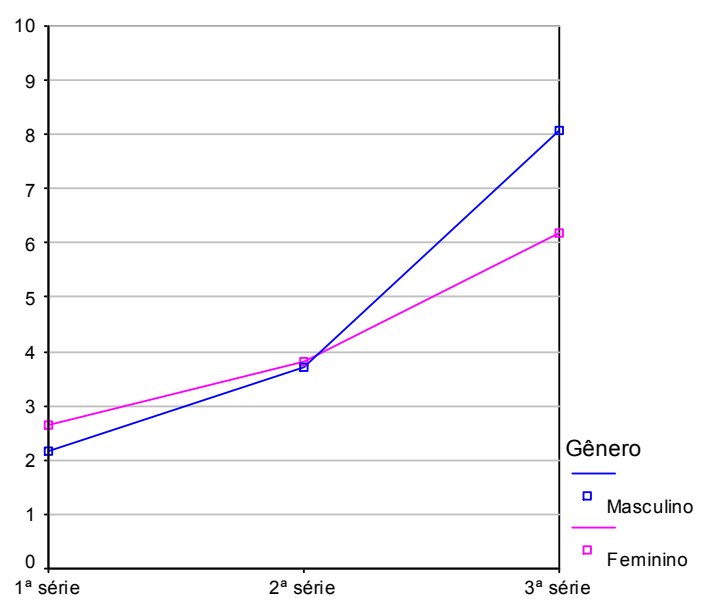

Figura 5: Nota média na prova de Problemas, por série e gênero.

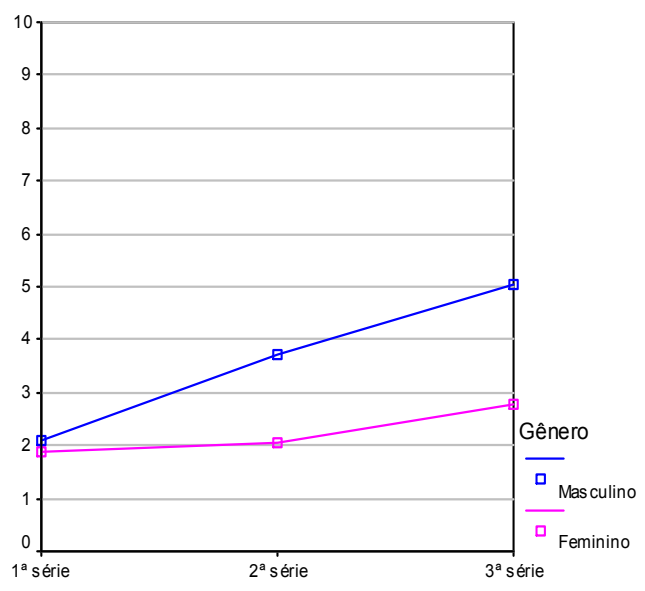

Fonte: Dados da pesquisa.

A Figura 6 ilustra a relação entre as notas nessas provas, de forma conjunta e separada por série. Quando se analisam todas as séries de forma conjunta, observa-se uma relação linear $(\mathrm{r}(95)=0,714 ; p=0,000)$. Essa relação, na $1^{\mathrm{a}}$ série, é ligeiramente mais forte $(\mathrm{r}(32)=$ 0,840; $p=0,000)$, porém se observam dois grupos de alunos, aqueles que têm um baixo desempenho nas duas notas, que é maioria, e cinco alunos que mostram um bom desempenho. $\mathrm{Na} 2^{\mathrm{a}}$ série $(\mathrm{r}(37)=557 ; p=0,000)$, essa correlação é mais fraca, pois se observam alunos que tiveram nota baixa na prova de algoritmos e que obtiveram notas razoáveis nos problemas e vice-versa. Já na $3^{\mathrm{a}}$ série $(\mathrm{r}(26)=0,771 ; p=0,000)$, a maioria dos alunos foi bem na prova dos algoritmos, mas variaram muito na nota de problemas.

Figura 6: Relação entre as notas em algoritmo e problemas por série. (continua)

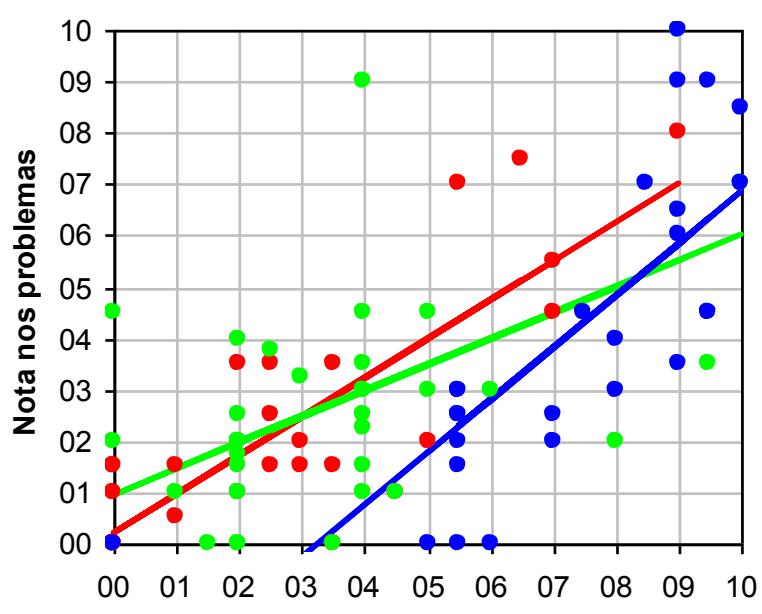

Nota nos algoritmos

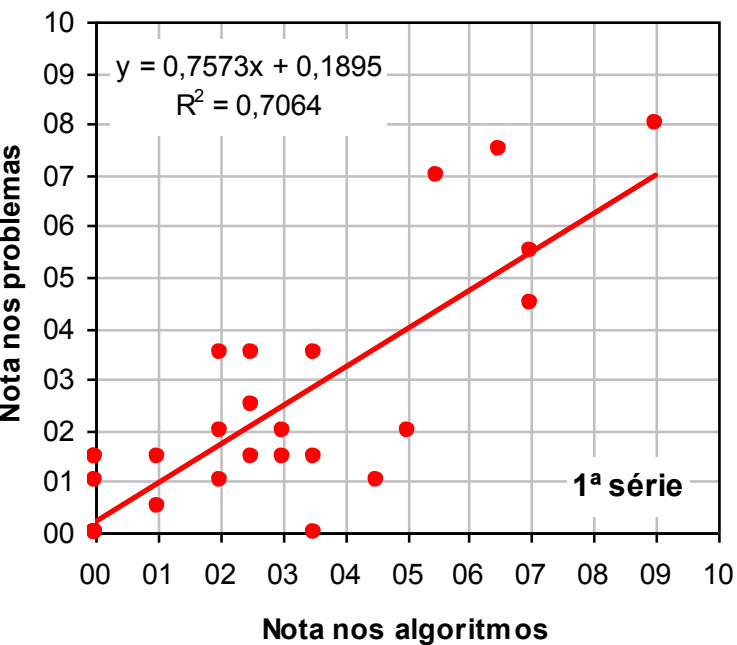

Nota nos algoritmos 
Figura 6: Relação entre as notas em algoritmo e problemas por série. (continuação)
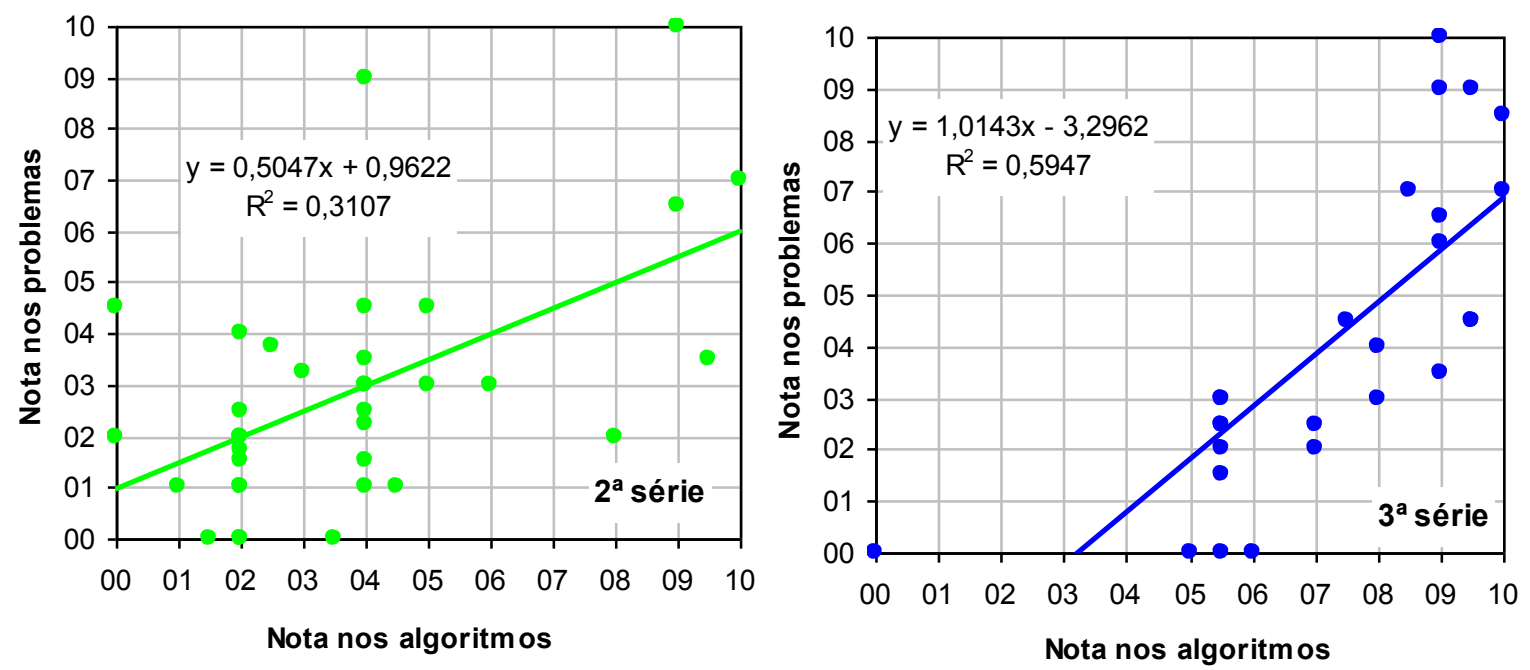

Fonte: Dados da pesquisa.

A Figura 7 mostra que não existem diferenças na relação por gênero, embora os indivíduos do gênero masculino tenham um desempenho ligeiramente superior, como já foi visto anteriormente.

Figura 7: Relação entre as notas em algoritmo e problemas por gênero.(continua)
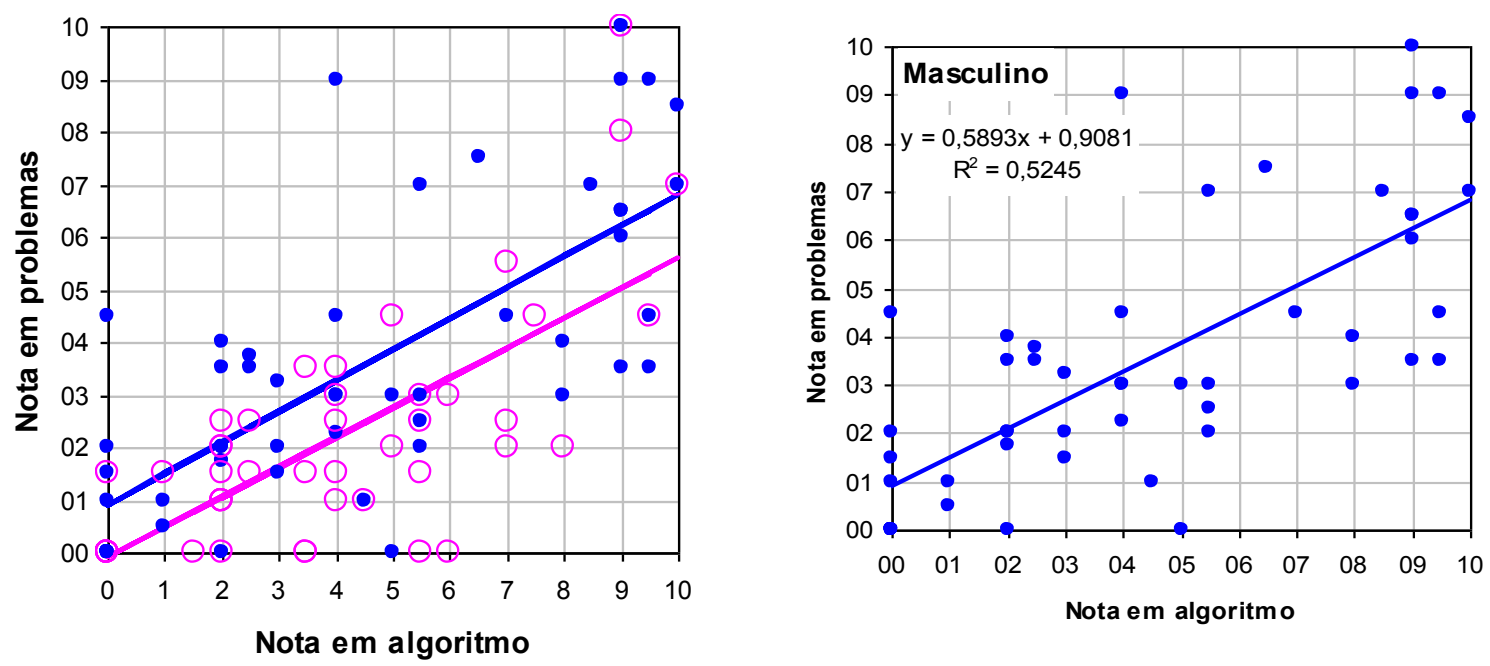
Figura 7: Relação entre as notas em algoritmo e problemas por gênero.(continuação)

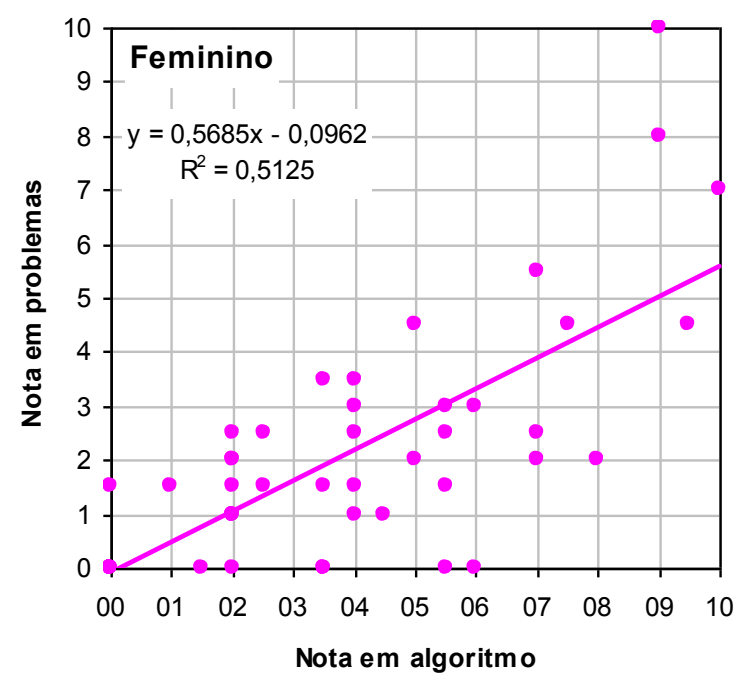

Fonte: Dados da pesquisa.

Quanto ao desempenho dos estudantes, pode-se concluir que este se relaciona mais diretamente com o desempenho na prova de algoritmos do que na solução de problemas; que o desempenho melhora segundo a série, principalmente na terceira, e que a média das atitudes em relação à Matemática diminui conforme a série, sendo que entre as meninas essa diminuição é mais acentuada.

Analisando-se as correlações entre as pontuações nas escalas e nas notas na prova de desempenho, nota-se que existe correlação entre as duas escalas e entre as notas. Já a correlação entre as notas e as escalas é mais fraca; a maior delas se deu entre a pontuação na escala de frações e a nota em problemas $(r(94)=0,532 ; p=0,000)$; em menor grau, entre a pontuação na escala de frações e a nota média $(r(94)=0,421 ; p=0,000)$ e entre a escala matemática e a nota em problemas $(r(94)=0,435 ; p=0,000)$.

Com relação aos resultados da prova conceitual, foi possível perceber que os alunos apresentaram dificuldades em realizar operações com frações de modo diferente, seja por meio de desenho ou por meio de frações equivalentes. A definição de fração também contemplou somente alguns dos significados centrais propostos por Nunes et al. (2003).

O primeiro exercício desta prova era composto por três questões que foram classificadas em acertou/ errou e o procedimento utilizado pelo aluno.

$\mathrm{Na}$ análise dos procedimentos foi citada a Regra do Peixinho, que consiste em multiplicar o numerador da $1^{\mathrm{a}}$ fração pelo denominador da $2^{\mathrm{a}}$. O número obtido será o numerador da nova fração. Em seguida, multiplica-se o denominador da $1^{\mathrm{a}}$ pelo numerador da 
segunda, obtendo-se o denominador da nova fração. $O$ desenho formado durante esse processo é o de um peixe.

Figura 8: Regra do Peixinho, de acordo com os alunos

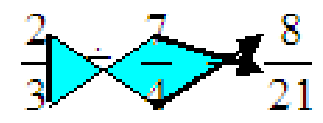

Fonte: Dados da pesquisa

$\mathrm{Na}$ letra A $\left(\frac{3}{10}+\frac{1}{4}\right)$ esperou-se que o aluno utilizasse as frações equivalentes ou representação gráfica para chegar à resposta. Entretanto, apenas 12 alunos acertaram o resultado e desenvolveram o procedimento de maneira adequada. Seis estudantes transformaram em decimais, 3 (três) utilizaram as frações equivalentes e o restante não indicou o procedimento claramente.

Deixaram a questão em branco, 23 alunos, o que representa cerca de $25 \%$ do total. Quanto aos erros, foram encontrados os seguintes:

1. O estudante somou os numeradores e denominadores $(16,84 \%)$

2. O estudante realizou o m.m.c. mesmo não sendo permitido - o que pode significar que não entendeu o solicitado ou não sabe fazer de outra forma $(14,74 \%)$

3. O estudante obteve uma resposta errada, mas não indicou o procedimento $(11,58 \%)$

4. O estudante utilizou desenho, mas os inteiros eram diferentes $(7,37 \%)$

5. O estudante somou os numeradores e multiplicou os denominadores/ utilizou a regra do peixinho/ Utilizou representação inadequada (como somar bolinhas com quadradinhos) $(2,11 \%$ cada $)$

6. O estudante descreveu um procedimento sem lógica/ Multiplicou em cruz e somou/ Somou os numeradores e subtraiu os denominadores/ Somou o numerador, fatorou os denominadores e somou/ Somou os numeradores e conservou o maior denominador/ Multiplicou a primeira fração por 3 e a segunda por 4. (1,05\% cada).

A letra B $\left(\frac{4}{5}-\frac{2}{3}\right)$ solicitou que os alunos fizessem a subtração de frações sem utilizar o recurso do m.m.c. O número de acertos novamente foi de 12 (doze). O número de brancos aumentou, representando $27,37 \%$ do total.

Os erros encontrados assemelham-se aos apresentados no exercício 1A (anterior):

1. O estudante subtraiu os numeradores e denominadores $(17,89 \%)$

2. O estudante utilizou o recurso do m.m.c. $(15,79 \%)$ 
3. O estudante utilizou desenho, mas os inteiros eram diferentes/ Não indicou o procedimento $(5,26 \%)$

4. O estudante subtraiu os numeradores e multiplicou os denominadores/ Tentou desenhar, mas não concluiu as ideias $(3,16 \%)$

5. O estudante utilizou a "Regra do Peixinho"/ Utilizou procedimento incorreto $(2,11 \%)$

6. O estudante subtraiu os numeradores, fatorou os denominadores e somou/ Subtraiu os numeradores e somou os denominadores/ Não concluiu/ Multiplicou em cruz e somou tudo $(1,05 \%)$.

A letra $C\left(\frac{3}{25}+\frac{2}{5}\right)$ apresentou resultados semelhantes à $1 \mathrm{~A}$ que solicitava adição de frações. Entretanto, apenas 9 (nove) alunos acertaram a resposta, indicando que o índice de acertos diminuiu.

Em relação aos principais erros, $16,84 \%$ dos alunos, somou numeradores e denominadores e $14,37 \%$ utilizaram o m.m.c. Aproximadamente $24 \%$ dos sujeitos deixaram o exercício em branco.

O segundo exercício (Escreva o que você entende por fração e dê exemplos) apresentou respostas que evidenciaram a falta de domínio do conceito de fração. Os resultados indicaram que: 21 (vinte e um) estudantes deixaram a questão em branco, 4 (quatro) alunos escreveram que não lembravam o conceito de fração e apenas 5 (cinco) sujeitos deram exemplos ou realizaram uma representação.

Onze alunos relacionaram a fração com uma divisão. Um sujeito entendeu que as frações são razões, o que se reporta a ideia de divisão. Outros 8 (oito) participantes indicaram que as frações representam "partes quebradas" cuja divisão resulta em número decimal.

Outra ideia de fração refere-se ao todo e suas partes. 25 (vinte e cinco) sujeitos afirmaram que "Fração é uma parte de um todo", o que pode levar a alguns equívocos se o inteiro não for dividido em partes iguais. Somente 5 (cinco) alunos indicaram que " é o todo dividido em partes iguais". Outro aluno respondeu que fração "É uma parte pequena de um número".

Quatro estudantes indicaram que "Fração é uma conta que faz m.m.c." e outro afirmou ser uma conta que subtrai.

No terceiro exercício, o aluno deveria indicar a fração correspondente às figuras destacadas. O primeiro desenho (figura 9) apresentou um todo dividido em partes não iguais. 
Diante da definição de frações, somente um aluno apontou que não seria possível indicar a fração correspondente à área hachurada, já que as partes não são iguais.

Figura 9: Desenho do exercício 3A

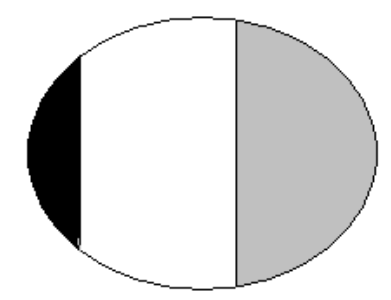

Fonte: Dados da pesquisa.

O restante dos sujeitos participantes da pesquisa, ou seja, 94 (noventa e quatro estudantes) responderam de maneira equivocada essa questão. $26 \%$ dos sujeitos deixaram a questão em branco. $17 \%$ dos estudantes não consideraram as duas regiões da figura, mas, somente, a parte em preto. $11 \%$ responderam $\frac{2}{3}$ justificando de maneira parecida com a do aluno que participou da entrevista:

\section{Aluno: Então seria 2/3, porque ele dividiu em 3 e pegou 2.}

Já a letra B (figura 10) apresentava um retângulo dividido em 4 (quatro) partes e destacadas apenas 2 (duas).

Figura 10: Desenho do exercício 3B

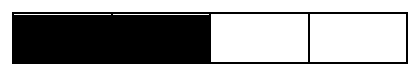

Fonte: Dados da Pesquisa

O número de sujeitos que acertaram essa questão foi de 73 (setenta e três). Destes 41 (quarenta e um) responderam $\frac{2}{4}$, não fornecendo a resposta de modo simplificado (fração irredutível). Nove alunos deixaram a questão em branco e um sujeito escreveu "Não Sei".

\section{Conclusões}

Quando se compara o desempenho dos sujeitos na solução de problemas e o desempenho dos mesmos na prova de algoritmo (com a utilização do m.m.c.), encontram-se melhores resultados na parte técnica. Entretanto, as médias ficaram bem abaixo do desejável 
para alunos do Ensino Médio. Na prova de algoritmo, a média das notas foi de 4,2632 e, na solução de problemas matemáticos, a média caiu para 2,9053.

Uma das dificuldades apresentadas pelos participantes durante a prova de Matemática (problemas) foi na obtenção da informação matemática através do enunciado. Alguns dos sujeitos não conseguiram identificar a operação correta e acabaram deixando de fazer ou resolvendo incorretamente o problema. Alves (1999) afirmou que os alunos encontram dificuldades na obtenção da informação matemática (o enunciado) e, nesse estágio, tendem ao erro. Esse mesmo resultado foi obtido por Pirola (2000), que evidenciou que os participantes, futuros professores que iriam ensinar matemática na escola básica, também apresentaram dificuldades na obtenção da informação matemática, que, segundo alguns autores, como Krutetskii (1976), é o primeiro estágio da resolução de problemas.

Comparando o desempenho dos sujeitos de acordo com a série e o gênero, de modo geral, percebem-se diferenças significativas somente por série $(F(2,89)=7,938 ; p=0,001)$. As interações entre série e gênero ou as diferenças por gênero não foram significativas.

Quanto ao desempenho dos sujeitos em relação ao gênero, foram encontrados resultados semelhantes em trabalhos como os de Utsumi (2000), Lima (2001) e Quintiliano (2005). Essas pesquisas também apontaram que o gênero não é uma variável confiável para determinar qual será o aproveitamento do estudante em Matemática. Dessa forma, a escola deve fornecer o mesmo tratamento para ambos os gêneros na sala de aula, já que o que existe é mais uma crença - a de que os meninos têm mais facilidade em Matemática - conforme o estudo de Brito (1996).

Uma preocupação evidenciada pelos participantes durante a realização das provas foi a de a resposta estar correta ou não. De acordo com Brito (2006), muitos professores, em atividades de solução de problemas, apenas corrigem a resposta final, não discutindo os procedimentos empregados pelos estudantes, o que não possibilita o "pensar sobre o pensado" (p. 27) e o desenvolvimento de uma reflexão produtiva. É comum, nas aulas de Matemática, que o professor retire problemas estereotipados dos livros didáticos e não proponha novos ou solicite a elaboração de problemas para o aluno.

$\mathrm{O}$ aluno que desenvolveu a autonomia para solucionar problemas, embora o ensino de Matemática valorize, muitas vezes, o aspecto mecânico por meio de fórmulas e modelos de problemas, ao "encontrar uma maneira de solucionar um problema usando procedimentos distintos dos padrões convencionais, evidencia um dos aspectos essenciais do pensamento matemático" (BRITO, 2006, p. 30). 
Dessa forma, o professor de Matemática deveria buscar a valorização de um "plano para a solução de problemas", mostrando aos alunos a importância de uma leitura atenta do enunciado do problema, da elaboração de uma estratégia e da avaliação da resposta obtida. É fundamental que ocorra uma reflexão por parte do professor de Matemática sobre o que ele entende e como trabalha a solução de problemas enquanto eixo estruturador da disciplina e, a partir disso, busque desenvolver atitudes positivas e a autonomia nos alunos.

Quanto ao ensino de frações, uma abordagem que ultrapassa a simples transferência da linguagem cotidiana para a científica, por meio de exercícios de manipulação de objetos ou relação com situações cotidianas que envolvem frações como divisão de pizzas ou chocolates, pode ocorrer por meio da (re)construção da história do conceito. Alguns estudos, como os de Prado (2000) e Catalani (2002), indicam que é necessário que os estudantes explorem a forma e conteúdo do conceito de fração. Para isso, resgatar a história das frações, mostrando aos estudantes as necessidades e impossibilidades que motivaram a construção de um novo campo numérico, pode fazer com que eles percebam a Matemática como construção humana, voltada para os interesses do homem.

Os números racionais, em especial as frações, devido a sua importância no currículo da Matemática, merecem maior atenção nos trabalhos produzidos, principalmente em relação às atitudes e sua influência no ensino. Desse modo, será possível que se encontrem novas possibilidades para o ensino, buscando a melhoria do desempenho dos estudantes, por meio de uma educação através da solução de problemas.

\section{Referências}

AIKEN, L. R. The effect of attitudes on performance in Mathematics. Journal of Educational Psychology, v. 52, n. 1, p. 19-24, 1961.

AIKEN, L. R.; DREGER, R. M. The effect of attitudes on Performance in Mathematica. Journal of Educational Psychology, Arlington, v. 52, n. 1, p. 19-24, 1961.

ALVES, E. V. Um Estudo Exploratório dos Componentes da Habilidade Matemática requeridos na Solução de Problemas Aritméticos por Estudantes do Ensino Médio. 1999. 186 f. Dissertação (Mestrado em Educação) - Universidade Estadual de Campinas, Campinas, 1999.

ARAUJO, E. A. Influência das habilidades e das atitudes em relação à matemática e a escolha profissional. 1999. 232 f. Dissertação (Mestrado em Educação) - Universidade Estadual de Campinas, Campinas, 1999. 
ARDILES, R.N. Um estudo sobre as concepções, crenças e atitudes dos professores em relação à Matemática. 2007. 236 f. Dissertação (Mestrado em Educação) - Universidade Estadual de Campinas, Campinas, 2007.

BEHR, M. et al. Rational-number concepts. In: LESH, R.; LANDAU, M. (Eds.) Acquisition of Mathematical Concepts and Processes. Orlando: Academic Press, 1983. p.91-126.

BRASIL. Ministério da Educação e do Desporto, Secretaria de Educação Média e Tecnológica. Parâmetros Curriculares Nacionais: Temas Transversais. Brasília: 1998.

BRITO, M. R. F. Um estudo sobre as atitudes em relação à Matemática em estudantes de $1^{\circ} \mathrm{e}$ $2^{\circ}$ graus. Trabalho de Livre docência. Faculdade de educação - UNICAMP. Campinas: 1996.

BRITO, M. R. F. (Org.). Solução de problemas e a matemática escolar. Campinas: Alínea, 2006. 280 p.

CATALANI, E. M. T. 2002. 216 f. A inter-relação forma e conteúdo no desenvolvimento conceitual da fração. Dissertação (Mestrado em Educação) - Universidade Estadual de Campinas, Campinas, 2002.

COLL, C. et al. Os conteúdos na reforma: ensino e aprendizagem de conceitos, procedimentos e atitudes. Tradução: Beatriz Affonso Neves. Artes Médicas. Porto Alegre: 1998. $182 \mathrm{p}$.

DOBARRO, V. Solução de problemas e tipos de mente matemática: relações com as atitudes e crenças de auto-eficácia. 2007. 215 f. Tese (Doutorado em Educação) Universidade Estadual de Campinas, Campinas, 2007.

ECHEVERRÍA, M. D. P. P. A Solução de Problemas em Matemática. In: POZO, J. I. A solução de problemas: aprender a resolver, resolver para aprender. Porto Alegre: ArtMed Editora, 1998. 178p.

GONÇALEZ, M. H. C. C. Relações entre família, o gênero, o desempenho, a confiança e nas atitudes em relação à matemática. 2000. 171 f. Tese (Doutorado em Educação) Universidade Estadual de Campinas, Campinas, 2000.

JESUS, M. A. S. As atitudes e o desempenho em operações aritméticas do ponto de vista da aprendizagem significativa. 2005. 207 f. Tese (Doutorado em Educação) - Universidade Estadual de Campinas, Campinas, 2005.

KIEREN, T. E. On the mathematical, cognitive and instructional foundations of rational numbers. In: R. A. Lesh (Ed.). Number and measurement: Papers from a research workshop. Columbus: ERIC/SMEAC, 1976, p. 101-144.

Five faces of mathematical knowledge building. Edmonton: Department of

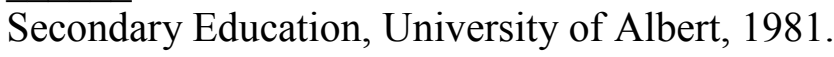


Rational and fractional numbers: From quotient fields to recursive understanding. In: T.P. Carpenter, E. Fennema \& T. A. Romberg (Eds.). Rational numbers: An integration of research. Hillsdale, NJ: Lawrence Erlbaum, 1993, p. 49-84.

KLAUSMEIER, H. J., GOODWIN, W. Manual de psicologia educacional: Aprendizagem e Capacidades Humanas. Tradução: Maria Célia Teixeira Azevedo de Abreu. São Paulo: Harper \& Row do Brasil, 1977

KRUTETSKII, V. A . The psychology of mathematical abilities in schoolchildren. IL: The Chicago University Press. Chicago: 1976. 605 p.

LIMA, V. S. Mapeamento cognitivo: um estudo do conceito de frações em estudantes de magistério e professores de $1^{\circ}$ grau (1 ${ }^{\mathbf{a}}$ a $4^{\text {a }}$ séries). 1996. 295 f. Dissertação (Mestrado em Educação) - Universidade Estadual de Campinas, Campinas, 1996.

LIMA, V. S. Solução de problemas: Habilidades matemáticas, flexibilidade de pensamento e criatividade. 2001. 190 f. Tese (Doutorado em Educação) - Universidade Estadual de Campinas, Campinas, 2001.

MACEDO, M. R. A família do ponto de vista psicológico: lugar seguro para crescer? Cadernos de Pesquisa, São Paulo, n. 91, p. 62-68, nov 1994.

MACIEL, A.; CÂMARA, M. Analisando o Rendimento de Alunos das Séries Finais do Ensino Fundamental e do Ensino Médio em Atividades Envolvendo Frações e Idéias Associadas. Bolema, Rio Claro, ano 20, n. 28, p. 163 a 177, 2007.

MERLINI, V. L. O Conceito de fração em seus diferentes significados: Um estudo diagnóstico com alunos de $5^{\mathbf{a}}$ e $\mathbf{6}^{\mathbf{a}}$ séries do Ensino Fundamental. 2005. 225 f. Dissertação (Mestrado em Educação Matemática). Pontifícia Universidade Católica de São Paulo, São Paulo, 2005.

NACARATO, A. et al. Números racionais: aspectos conceituais, o papel da linguagem e dos materiais manipulativos. In: Revista Horizontes, Bragança Paulista, v.22, n. 1, p. 53-64, jan/jun 2004.

NORUSIS, M. J. SPSS for Windows Base System User's Guide Release 6.0. Chicago: SPSS Inc., 1993.

NUNES,T.; BRYANT, P. Crianças Fazendo Matemática Ed. Artes Médicas, Porto Alegre, 1997. $248 \mathrm{p}$.

NUNES, T. et al. The effect of situations on children's understanding of fractions. Trabalho apresentado no encontro da British Society for Research on the Learning of Mathematics. Oxford, Jun 2003.

OLIVEIRA, R.G. Aprendizagem de frações: Uma análise comparativa de dois processos diferentes de ensino na $5^{\text {a }}$ série do $\mathbf{1}^{\mathbf{0}}$ grau. 1996. 165 f. Dissertação (Mestrado em Educação - Universidade Estadual de Campinas, Campinas, 1996. 
PIROLA, N. A. Solução de problemas geométricos: dificuldades e perspectivas. 2000. 218 f. Tese (Doutorado em Educação) - Universidade Estadual de Campinas, Campinas, 2000.

POLYA, G. A arte de resolver problemas: Um novo aspecto do método matemático. Ed. Interciência. Rio de Janeiro: 1986. 224 p.

POSTIGO, Y.; PÉREZ ECHEVERRÍA, M. P.; SANZ, A. Un estudio acerca de las diferencias de género en la resolución de problemas científicos. In: Enseñanza de las Ciencias, Barcelona, v. 17, n. 2, p. 247-258, jun 1999.

PRADO, E. P. A. 2000. Uma reflexão sobre formação de professores no Ensino da Matemática. Dissertação de mestrado. Pontifícia Universidade Católica de São Paulo, 2000.

QUintiliano, L. C. Conhecimento Declarativo e de Procedimento na solução de problemas algébricos. 2005. 159 f. Dissertação (Mestrado em Educação) - Universidade Estadual de Campinas, Campinas, 2005.

SANTOS, A. O conceito de fração em seus diferentes significados: Um estudo diagnóstico junto a professores que atuam no Ensino Fundamental. 2005. $196 \mathrm{f}$. Dissertação (Mestrado em Educação Matemática) - Pontifícia Universidade Católica de São Paulo, São Paulo, 2005.

STERnBERG, R. J. Psicologia Cognitiva. Tradução de Maria Regina Borges. Porto Alegre: Artes Médicas Sul, 2000. 494 p.

UTSUMI, M. C. Atitudes e habilidades envolvidas na solução de problemas algébricos: Um estudo sobre o gênero, a estabilidade das atitudes e alguns componentes da habilidade matemática. 2000. 246 f. Tese (Doutorado em Educação) - Universidade Estadual de Campinas, Campinas, 2000.

VIANNA, O. A. O componente espacial da habilidade matemática de alunos do Ensino Médio e as relações com o desempenho escolar e as atitudes em relação à Matemática e à Geometria. 2005. 279 f. Tese (Doutorado em Educação) - Universidade Estadual de Campinas, Campinas, 2005. 